\title{
La experiencia psicológica del agresor en el conflicto violento*
}

\section{The Psychological Experience of the Aggressor in Armed Conflicts}

María Prieto-Ursúa*

Universidad Pontificia Comillas, Madrid, España https://orcid.org/0000-0001-7562-0923

Ángela Ordónez Carabaño ${ }^{* * *}$

Universidad Pontificia Comillas, Madrid, España https://orcid.org/0000-0001-7552-1300

Artículo de investigación

Fecha de recepción: 11 de septiembre de 2019

Fecha de aceptación: 26 de octubre de 2019

\section{Para citar este artículo}

Prieto-Ursúa, M. y Ordóńez, A. (2020). La experiencia psicológica del agresor en el conflicto violento. Campos en Ciencias Sociales, 8(1), 325-348. DoI: https://doi. org/10.15332/25006681/5722

* El artículo forma parte de un estudio de investigación llevado a cabo en Ruanda con la ayuda de la Universidad Pontifica Comillas, en el marco de la línea de investigación sobre Reconciliación que fomenta dicha institución.

** Autora de correspondencia. Doctora en Psicología. Correo electrónico: mprieto@comillas.edu

*** Psicóloga general sanitaria. Correo electrónico: aordonez@comillas.edu 


\section{REsUMeN}

El artículo se centra en la experiencia del perdón desde la perspectiva del individuo que ha agredido violenta e injustamente a otro, a partir del modelo de desconexión moral y el proceso de perdón a sí mismo después cometer la agresión. Además, se detallan los pasos imprescindibles para iniciar y completar este proceso, y los puntos más difíciles o los peligros que pueden llevar a un "falso" perdón a uno mismo. Se ofrece un análisis cualitativo de entrevistas en profundidad llevadas a cabo en Ruanda con agresores que participaron activamente en el genocidio de Ruanda y con sus víctimas. Se confirma la aplicabilidad de los conceptos básicos del marco teórico en este caso concreto, tanto los referidos a la presencia de mecanismos de desconexión moral como los referidos a los pasos necesarios, según la psicología del perdón, para llegar a encontrarse con las víctimas, pedir perdón y empezar un camino de reconciliación.

Palabras clave: conflicto social, genocidio, paz, psicología social.

\section{Abstract}

This article focuses on the aggressor's experience of forgiveness from the perspective of an individual who has violently and unjustly assaulted another, considering the Moral Disengagement Model and the self-forgiveness process that follows the aggression and describing the essential steps to start and complete this process, as well as the most difficult threats or challenges that can lead to a "false" self-forgiveness. We present a qualitative analysis of in-depth interviews with aggressors who were actively involved in the Rwandan genocide, and their victims. The suitability of the basic concepts of the theoretical framework is confirmed in this particular case, both the concepts relating to the presence of moral disengagement mechanisms and those relating to the necessary steps, according to the psychology of forgiveness, to encounter the victims, ask for forgiveness, and open a path for reconciliation.

Keywords: social conflict, genocide, peace, social psychology. 


\section{INTRODUCCIÓN}

Esta investigación se enmarca en el estudio psicológico de los procesos de paz y reconciliación. En concreto, su objetivo es comprender los mecanismos psicológicos personales que pueden dificultar o movilizar la participación del agresor en el proceso de reparación y reconciliación. Nuestro estudio, centrado en el contexto del posgenocidio de Ruanda, confirma la relevancia de los mecanismos de desconexión moral y la asunción de responsabilidad para poner en marcha el proceso de perdón a uno mismo, y sugiere la conveniencia de la aplicación de estos conceptos a otros posibles contextos de conflicto y posconflicto internacionales.

\section{Marco conceptual}

Los conflictos suelen comenzar con situaciones en las que una parte o ambas ven que sus necesidades básicas de supervivencia, seguridad, libertad, dignidad, y otras no se pueden cubrir, con lo que se empieza a percibir una amenaza seria a su integridad y bienestar. Pero además de las amenazas, reales o percibidas, en casi todos los conflictos violentos se dan también elementos personales que facilitan que el conflicto aparezca, se mantenga e, incluso, se agrave.

Entre otros muchos, la psicología describe la aparición de relatos que distinguen entre nosotros (víctimas) y ellos (agresores) como el primer paso del camino que lleva al enfrentamiento. Como consecuencia de estas formas de entender al otro surgen narrativas victimistas, en las que nosotros siempre somos las víctimas que no solo hemos sufrido más que el otro, sino que nuestro sufrimiento es absolutamente inmerecido e injusto. Es frecuente también la polarización, por la que las posturas tienden a reducirse cada vez más a dos esquemas opuestos y excluyentes; desde ella solamente se entienden dos formas de actuación: a favor del grupo o poniendo en peligro al grupo. Es decir: "o estás conmigo, o estás en contra de mí". 


\section{La desconexión moral}

Entre todos estos procesos (y otros muchos de naturaleza política, social, económica, etc.), para entender la escalada violenta de un conflicto nos parecen de especial interés los mecanismos de desconexión moral (Bandura, 1999). Como han señalado los estudios sobre el desarrollo moral y la socialización de Jean Piaget o Lawrence Kohlberg, sabemos que los seres humanos desarrollamos en el proceso evolutivo una serie de principios morales que nos ayudan a responder a diferentes situaciones conforme la expectativa social.

Según Bandura (1999), el sistema regulador moral se adquiere en dos fases: en primer lugar, a través de las normas y los castigos procedentes del exterior y, finalmente, asimilando estas normas como propias, donde nos aplicamos consecuencias según nuestro comportamiento: nos reforzamos a nosotros mismos cuando nuestras conductas son coherentes con nuestros valores y nos autocastigamos cuando no lo son. Este sistema regulador moral es el que se encarga de motivarnos hacia el comportamiento humanitario y de frenar la emisión de conductas censurables (Bandura, 1999; 2002). Es decir, según Bandura, cuando las personas siguen sus criterios y valores morales, construidos durante el proceso de socialización, sienten satisfacción y bienestar, mientras que romperlos supone experimentar una sensación de incoherencia (disonancia cognitiva) y procesos de autocensura y autocastigo, lo que supone un elevado grado de malestar.

El sistema de regulación moral no está activado de forma constante; puede desactivarse. Existe una serie de mecanismos psicológicos mediante los que este sistema puede ser activado o desactivado de forma selectiva (Bandura, 1990), lo cual permite la realización de actos inmorales mientras mantenemos la creencia de ser "buenos". La violencia extrema dirigida hacia personas requiere la modificación de nuestros imperativos morales, y eso solo es posible si ponemos en marcha mecanismos de desconexión moral muy poderosos. Hay cuatro formas principales de conseguir desconectar el control moral interno de la conducta incorrecta.

Una de ellas es redefinir la conducta, por ejemplo, comparándola con otras peores o utilizando un lenguaje eufemístico; esto no solo evita el autocastigo, sino que aporta 
aprobación personal y sentido. Mediante la "comparación ventajosa", podemos afirmar que la violencia evita más daño del que causa y, por tanto, es útil (Bandura, 2002) o que la conducta no es tan mala en comparación con otras que son mucho peores. Por otra parte, el lenguaje crea y transforma la realidad, da forma a los patrones de pensamiento en los que se basan nuestras acciones. Por ello, dependiendo de cómo sea llamada una acción, en función del lenguaje que empleemos para nombrarla y describirla, esta se convertirá en moralmente aceptable o no (Bandura, 1990). Mediante este mecanismo, se le quita a la acción lo reprochable y se la etiqueta como algo correcto, respetable u honorable, con lo cual el individuo que la realiza se libera de su responsabilidad y sentimiento de culpa (de la autocensura).

Otra forma de seguir convencidos de ser los buenos es restar responsabilidad cuando agredimos mediante tres mecanismos. El primero de ellos es la difusión de la responsabilidad, a través de la cual disminuye la percepción de responsabilidad si se actúa respaldado por un grupo, o si las decisiones se toman en grupo, o si las conductas dañinas se dividen en muchos pasos y la persona solamente se ha ocupado de uno de ellos; así, se facilita la desinhibición y sentirse menos responsable de la propia conducta: "no lo he hecho yo solo".

En segundo lugar, podemos utilizar el desplazamiento de la responsabilidad, donde la persona transfiere su moral hacia una autoridad externa que considera legítima: “yo solo cumplía órdenes". La percepción de la responsabilidad es menor si las consecuencias de la conducta se presentan como inintencionadas o inevitables debido a la situación (Bandura, 1990). Otro mecanismo es el servicio de un valor, con el cual se justifica la agresión bajo principios de orden moral superior: "nuestra lucha está intentando conseguir algo muy noble”.

La desconexión moral también sucede al minimizar o ignorar las consecuencias dañinas de la propia acción. En primer lugar, podemos hacer como si las consecuencias de sus actos no existiesen y desacreditar las evidencias de estas (Bandura, 1990), o bien, minimizarlas. Asimismo, es más fácil que alguien no se sienta culpable cuando se centra en los beneficios de la acción y, sin embargo, no recuerda sus efectos negativos (Bandura, 1990). De esta manera, no existen motivos para que nuestra autocensura 
se active (Bandura, 2002). Por ejemplo, se ha descrito el llamado egoismo de la victimización: la inhabilidad de un grupo para simpatizar con las víctimas de otro a causa de sus propios traumas (Mack, 1990). Además, existe siempre un proceso de habituación a lo desagradable de las consecuencias de la agresión: disminuye nuestra respuesta de malestar después de llevar a cabo sucesivos actos violentos.

La cuarta forma de desactivar el control moral consiste en envilecer a la víctima mediante la culpa o la devaluación. Es generalmente más aceptable dirigir la agresión a personas consideradas como opresoras o agresoras. Cuando se culpa a la víctima de ataques previos más graves, nos convertimos en las víctimas reales y primeras, y nuestra violencia es una simple actuación en legítima defensa, no un ataque. En esta fase, es frecuente recordar agresiones recibidas (cometidas por el otro) interpretadas siempre como "peores" y más graves que las nuestras, porque nos parece que nosotros no hacemos tanto daño como ellos. Es decir, se crea una versión de los hechos donde el enemigo es el principal causante de la situación (Sabucedo, Blanco y de la Corte, 2003).

Sin embargo, en ocasiones la acción violenta es difícil de justificar, como en el caso de víctimas inocentes, de modo que se utiliza una técnica diferente a la de la culpa, como la deslegitimación y despersonalización de la víctima. Percibir al otro como humano o similar a uno mismo activa emociones vicarias empáticas. Mediante la deshumanización se consigue no ver a los otros como personas con sentimientos, esperanzas y preocupaciones, sino como objetos subhumanos, lo que facilita la falta de control moral sobre nuestra conducta. Dejamos de verlo como un igual, como una persona, como un ser humano, y empezamos a percibirlo como alguien poco valioso o, por lo menos, menos valioso que nosotros.

Para conseguirlo, podemos definirlo con características "inhumanas", como alguien lleno de crueldad o falta de compasión, y comenzamos a asociarlo con otros grupos con valoración social y cultural negativa, como nazis, fascistas o imperialistas, o incluso compararlo con animales, o con seres malévolos. 
En la tabla 13.1 se resumen los mecanismos que se presentan de forma esquemática:

Tabla 13.1. Resumen de los mecanismos de desconexión moral

\begin{tabular}{|c|c|c|c|c|}
\hline Mecanismo & $\begin{array}{l}\text { Redefinición de } \\
\text { la conducta }\end{array}$ & $\begin{array}{l}\text { Disminución de } \\
\text { la responsabilidad }\end{array}$ & $\begin{array}{l}\text { Minimización de } \\
\text { las consecuencias }\end{array}$ & $\begin{array}{l}\text { Envilecimiento } \\
\text { de la víctima }\end{array}$ \\
\hline \multirow[t]{4}{*}{ Estrategias } & \multirow{2}{*}{$\begin{array}{l}\text { Comparación } \\
\text { ventajosa }\end{array}$} & Desplazamiento & \multirow[t]{3}{*}{ Negación } & Culpar a la víctima \\
\hline & & Difusión & & Deslegitimación \\
\hline & $\begin{array}{l}\text { Lenguaje } \\
\text { eufemístico }\end{array}$ & & & Despersonalización \\
\hline & $\begin{array}{l}\text { Justificación } \\
\text { moral }\end{array}$ & & & \\
\hline
\end{tabular}

Fuente: elaboración propia.

\section{La desconexión moral en el caso de Ruanda}

En el caso de Ruanda podemos encontrar los cuatro mecanismos de desconexión moral planteados por Bandura. Durante cien días se mató a sangre fría y de formas inimaginables. Para que un grupo tan grande de personas se alzara con tal violencia, fue necesario poner en marcha todas las formas posibles que tiene la psicología humana para hacer una evaluación de nuestros actos violentos que permitiera mantener intacta nuestra percepción moral como seres íntegros y esencialmente buenos. La violencia durante aquellos días pasó a ser vista como correcta, lo que redefinió los asesinatos como un trabajo necesario que permitiera conseguir un bien mayor, la "solución final" después de haber intentado otros caminos, conque esta era la única alternativa. Dicho "trabajo" estaba al servicio de un bien mayor: garantizar la seguridad y la libertad de los hutus y asegurar así que la historia de opresión no volvería a repetirse. El beneficio esperado era un futuro de paz en el que no tendrían que volver a competir por sus derechos.

Con frecuencia, las masacres se perpetraron en grupo, y se retuvieron a las víctimas en edificios grandes y sin salida, confinándolos en iglesias o estadios. La actuación de los interahamwe (los que matan juntos) permitía sentir el respaldo y la pertenencia al grupo, pero también diluir la responsabilidad de sus actos individuales. La idea de 
que no es uno mismo el que asesinó a una persona, sino que lo hizo todo un grupo, también permite que la responsabilidad se divida entre todos, atenuando así la culpa. Además, muchos de los agresores respondían a las órdenes de un superior, con lo que se desplazaba la responsabilidad hacia quien ordenaba los ataques; en muchas ocasiones, se amenazaba de muerte a quienes no querían participar de las masacres.

Se han documentado muchos casos concretos de perpetradores del genocidio que llegaron a habituarse a la violencia durante esos días. Personas que nunca habían cometido un crimen y que lograron distanciarse tanto emocionalmente que sus víctimas se convirtieron tan solo en números.

Por último, durante años se había ido alimentando la imagen de los tutsis como culpables. Esta narrativa de los otros como seres viles y opresores permitía entender el genocidio como una actuación en legítima defensa, no como un ataque. Esto facilitó desplazar la culpa hacia toda la comunidad tutsi, pero a la hora de asesinar a víctimas inocentes, personas concretas, mujeres, niños, el mecanismo psicológico principal fue la devaluación. Se referían a los tutsis como inyenzi (cucarachas), animales que no merecían ser tratados con la dignidad de las personas.

\section{La desconexión moral y el perdón a uno mismo}

Como vemos, la negación del error o de un acto inmoral no es algo patológico o inmoral; el ser humano dispone de una serie de procesos complejos, potencialmente no conscientes, que trabajan para protegerle contra la realidad de sus propias acciones y reducir el malestar emocional que resulta de reconocer que se ha cometido una transgresión. Estos mecanismos de desconexión moral protegen nuestra identidad, nuestra imagen, ante actos o comportamientos que podrían amenazarla. Algunos autores los incluyen dentro del conjunto de procesos protectores que han llamado "sistema psicológico inmune" (psychological immune system) (Gilbert et al., 1998) que defiende nuestro yo de eventos negativos o fracasos, de forma que consiguen hacer a las personas menos atentas o receptivas a la información negativa, y las capacita para perseverar y vivir relativamente felices con ellas mismas y sus situaciones. 
Sin embargo, evitar la responsabilidad dificulta el proceso de perdón a uno mismo. Culpando al exterior, o justificando sus acciones, o evitando toda situación o persona que recuerde a la ofensa se consigue neutralizar la culpa y, al no verse culpable, el ofensor no necesita perdonarse ya que niega haber hecho nada malo (Fisher y Exline, 2006; Hall y Fincham, 2005). La negación puede incluir tanto la negación del hecho, de lo incorrecto del hecho, de la importancia del hecho o del daño causado por el hecho.

Cuando el ofensor llega a un estado de consideración positiva de sí mismo después de un comportamiento incorrecto a través de estos mecanismos defensivos, se trata de un "falso perdón a uno mismo" (pseudo self-forgiveness). Para poder perdonarse a uno mismo en el contexto de una transgresión es fundamental asumir la responsabilidad.

\section{El perdón a uno mismo}

En ocasiones el agresor deja de protegerse, o los mecanismos de desconexión moral dejan de funcionar, y entonces debe enfrentarse a la inmoralidad de su acción, al daño que ha causado, al error cometido. Solo entonces puede ponerse en marcha el proceso de perdón a uno mismo: cuando se deja de negar o justificar la acción.

Cuando el sujeto comete una ofensa, suele experimentar culpa y remordimiento, los principales motivadores de cambio y reparación relacional (Woodyatt y Wenzel, 2013). Este malestar emocional tras una transgresión indica que el sujeto percibe lo que ha hecho como distinto de sí mismo (Dillon, 2001), muestra lo mucho que el ofensor valora la relación con la víctima o a la víctima misma, reduce la distancia con los demás tras la ofensa y puede impedir que el ofensor vuelva a violar sus valores y repetir el daño (Dillon, 2001).

Una vez el sujeto experimenta este malestar, hay dos posibles respuestas o formas de afrontar el hecho de haber cometido una ofensa. La primera forma en la que el sujeto puede reaccionar es autoculparse en exceso (autocondenación). Es posible y necesario distinguir entre remordimiento (beneficioso para sentir arrepentimiento y humildad) y autocondenación (Fisher y Exline, 2006). El perdón que nace de la culpa 
y el remordimiento por lo que se ha hecho sería un perdón genuino. Sin embargo, en ocasiones la persona, tras el error, siente o cree que es intrínsecamente mala o indigna. $\mathrm{Su}$ acción inmoral se interpreta como un indicador de su (escaso) valor como persona. Esto no le lleva a responsabilizarse o a hacer esfuerzos para cambiar (Fisher y Exline, 2006), sino a altos niveles de vergüenza y deseos de castigarse a uno mismo, a tendencias depresivas y a la rumiación negativa (estar continuamente recordando el error cometido), y también lleva a la evitación de situaciones sociales y de relaciones. En esta situación, el autoperdón es irrelevante para el sujeto: la persona está más centrada en su propio malestar que en el de la víctima. Para aceptar el perdón antes necesita aceptarse a sí mismo.

La segunda forma en la que el sujeto puede reaccionar ante el error o la ofensa es afrontar el daño causado y llevar a cabo una restauración compensativa. Solo esta forma de afrontar la ofensa cometida sería verdadero o genuino autoperdón (Woodyatt y Wenzel, 2013). En el proceso de autoperdón genuino se reconoce la culpabilidad, el valor de la víctima, se experimentan las emociones asociadas, y surgen actitudes y comportamientos que encaran la ofensa, buscan enmendar el daño; en el proceso, afirma su identidad moral ante la víctima, la comunidad y él o ella misma, y recupera su imagen como buena persona (se perdona a sí mismo) (Wenzel, Woodyatt, y Hedrick, 2012).

Como vemos, el proceso de autoperdón comprende dos dimensiones: una dimensión externa, interpersonal, relacionada con la comunidad, la situación ofensiva y la víctima; y otra interna, intrapersonal, relacionada con la autoestima, el autoconcepto y la propia identidad. Un verdadero autoperdón debería conllevar cambios que produzcan ambos tipos de restauración.

Cornish y Wade (2015) comparten una definición del perdón a uno mismo, que recoge estos contenidos del perdón genuino: un proceso en el que la persona, primero, acepta la responsabilidad de haber dańado a otra; segundo, expresa remordimiento mientras reduce la vergüenza; tercero, se implica en la restauración a través de conductas reparadoras, intenta cambiar los patrones de conducta que le llevaron a la ofensa y vuelve a comprometerse con sus valores; y cuatro, alcanza un renovado 
autorespeto, autocompasión y autoaceptación, gracias a lo cual consigue en todo el proceso un crecimiento moral.

Hemos revisado, pues, los dos modelos teóricos que guiarán nuestro estudio sobre la experiencia del agresor en un conflicto violento como el genocidio de Ruanda. Nuestro objetivo es comprobar la presencia de los mecanismos descritos en el proceso personal llevado a cabo por agresores que participaron en el conflicto, para analizar la pertinencia de estos modelos en la comprensión de dicho proceso.

\section{Metodología}

\section{Análisis fenomenológico interpretativo}

Nos servimos del sistema de análisis fenomenológico interpretativo (AFI) para explorar la experiencia del proceso de perdón a uno mismo de los agresores entrevistados y cómo los talleres para facilitar el proceso de reconciliación entre víctimas y perpetradores del genocidio podían influir en dicho proceso de autoperdón. El objetivo principal de este enfoque cualitativo es analizar experiencias personales. Recoge, por tanto, experiencias vividas en lugar de contenidos preestablecidos por marcos teóricos ya existentes. Esta metodología es especialmente valiosa en investigación de cuestiones muy complejas y procesos que difieren ampliamente en función de la experiencia personal y del recorrido individual de cada sujeto, como ocurre con el perdón a uno mismo en casos de violencia extrema, como ocurre en el contexto del genocidio ruandés (Smith y Osborn, 2015).

Consecuentemente, este tipo de análisis comprende tanto análisis fenomenológicos como interpretativos (Smith, Flowers, y Larkin, 2009). El componente fenomenológico describe la densidad de un fenómeno a través del estudio profundo de la explicación que una persona hace sobre él y del significado que esa persona le otorga a ese determinado hecho. Por otro lado, el proceso interpretativo tiene como objetivo comprender el relato de la persona entrevistada mediante la comprensión del contexto en el que vive. 


\section{Participantes}

Diez personas fueron entrevistadas, cinco parejas de víctimas del genocidio y el que había sido su agresor. Tres de las cinco víctimas eran mujeres y todos los agresores eran hombres. Todos ellos habían sobrevivido al genocidio y habían pasado por los talleres para facilitar la reconciliación organizados por Asociación Modeste et Innocent AMI.

Todos los sujetos de nuestro estudio han pasado por el proceso de reconciliación de la AMI, que trabaja desde su filosofía ubuntu (que significa bondad y don). Tienen dos presupuestos teóricos de los que parten: una primera aproximación cuyo objetivo es sanar a la persona (el poder interno correcto) y una segunda para sanar las relaciones (amataba). En la primera se incide en los mecanismos de desconexión moral, que será necesario ir desmontando para facilitar la asunción de la responsabilidad, y en la segunda, más enfocada al proceso de reconciliación con sus víctimas, es donde se aborda el perdón a uno mismo.

La primera aproximación (el poder interno correcto) consiste en la mejora de los niveles de conciencia y reconocimiento. Categorizan a las personas en cuatro niveles de conciencia, de menor a mayor. El más básico (“yo sociocultural”) sería el propio de los agresores durante el genocidio, desconectados de su identidad moral, que niegan la responsabilidad última de los actos cometidos y afirman que no hacían otra cosa que obedecer a la autoridad que lo ordenaba. La persona que se encuentra en este nivel estaría centrada en la sociedad, sin pensar en su propio deseo, criterio y racionalidad; únicamente ejecuta las órdenes de otros que le dicen lo que tiene que hacer. El siguiente nivel ("yo individualista"), con un poco más de conciencia, sería aquel en el que las personas actúan movidas por su propio beneficio. Ya no se dejan arrastrar por otros, pero tampoco actúan en detrimento de su propio interés. En el tercer nivel ("individuo individualizado") la persona sabe reconocer quién es y sabe que es alguien que vive dentro de una sociedad más grande que él mismo, tiene respeto a su vida, se hace responsable de sus propias acciones y toma sus propias decisiones, conoce sus valores y reconoce los valores de otros, reconoce su propio valor y el valor de otros. Es imprescindible que los agresores lleguen a este nivel de conciencia para poder asumir lo que han hecho. Por último, el "nivel 
transpersonal", ya es un grado suficiente de conciencia para poder iniciar un proceso de reconciliación. Las personas que alcanzan este cuarto nivel se interesan por las cosas que van más allá de ellos mismos y que benefician a otros (el altruismo y el comportamiento prosocial). La persona que alcanza este nivel no solo es capaz de reparar lo que ha hecho y perdonarse a sí mismo, sino que se convierte en agente de paz para otros.

Tras este proceso los agresores pasan a la intervención para facilitar el proceso de reconciliación, denominada amataba. Durante estas sesiones, cada grupo escribe las acusaciones que tiene contra el otro grupo; luego, se intercambian y se discuten en cada grupo para tratar de entender el punto de vista del otro y ayudar así a los agresores a profundizar en el conocimiento y reconocimiento del daño cometido. Después de un mes trabajando por separado, ambos grupos finalmente se encuentran y escuchan de primera mano las acusaciones que todavía tienen pendientes. El agresor puede perder poco a poco el miedo a la víctima (fruto de la deshumanización a la que la habría sometido en el tiempo previo al conflicto), pueden llegar a comprender la experiencia de aquel al que una vez consideraron menos que humano (mecanismo de desconexión moral) y pueden ver en las víctimas mucho más que odio, crítica y rechazo. Así, el encuentro entre grupos ocurre y, a partir de ahí, el diálogo, la escucha, la rehumanización del otro, las disculpas y el perdón. Para que este contacto entre grupos pueda darse, es necesario encontrar un lugar seguro para ambos, llamado amataba en la lengua local, el kinyarwanda, palabra que también da título a estos talleres.

Al final, todos se comprometen con el grupo como un proceso largo que conduce a la reconciliación. A menudo comienzan alguna actividad económica conjunta que les mantiene en contacto en un ambiente de cooperación y confianza, como, por ejemplo, comprar una tierra y cultivarla juntos o ayudarse mutuamente con sus negocios. Trabajar en plano de igualdad en un proyecto común permite al agresor reconocer la humanidad de la víctima y ayuda a los agresores a recuperar una imagen de sí mismos como buenas personas dignas de confianza (al menos en esa tarea concreta). 
Todas las parejas de víctima y agresor entrevistadas eran vecinas durante el genocidio. No obstante, dos de ellas tenían una relación aún más estrecha, una víctima y su agresor eran profesores a tiempo parcial en la misma escuela, y en el caso de otra pareja eran amigos de la infancia.

\section{Procedimiento}

El Ministerio de Educación de Ruanda (Subdirección de Ciencia, Tecnología e Investigación) concedió permiso para llevar a cabo esta investigación. La Asociación Modeste et Innocent facilitó el acceso a parejas de víctima y agresor que habían participado en talleres para facilitar la reconciliación realizados por esta asociación a lo largo de los últimos diez ańos en la ciudad de Butare. Los participantes fueron entrevistados en febrero de 2018 y todas las entrevistas se llevaron a cabo en la asociación. El consentimiento informado se obtuvo verbalmente antes de comenzar las entrevistas, cada una de ellas duró entre 20 a 30 minutos. En todas las entrevistas se encontraba presente la pareja de víctima y su agresor, simultáneamente, y todas ellas se llevaron a cabo con la ayuda de un intérprete de la lengua local (kinyarwanda) al inglés, y fueron transcritas por dos investigadores y posteriormente contrastadas para confirmar la fiabilidad.

Nos servimos de una entrevista semiestructurada como guía para conducir la entrevista con dos preguntas abiertas: ¿podrían hablarnos de su propia experiencia de reconciliación?, ¿cómo es su relación ahora, después de pasar por el proceso de los talleres Amataba?

Además, contamos con cuatro preguntas más afinadas para poder profundizar en la experiencia de los entrevistados: ¿cree que la justicia es un requisito para el perdón?, ¿sería posible que ustedes continuaran trabajando juntos, pero sin haberse perdonado?, ¿hay algo que les ayudara especialmente durante el proceso de reconciliación?, y ¿cuáles fueron los desafíos que tuvieron que afrontar durante el proceso? 


\section{RESUlTADOS Y DisCUSIÓN}

A continuación, presentamos los resultados del Análisis Fenomenológico Interpretativo, seleccionando aquellas categorías que tienen que ver con el proceso que vive el agresor, es decir, aquellas relacionadas con la agresión (mecanismos de desconexión moral) y con el proceso de perdón a sí mismo. Describimos brevemente cada una de las categorías presentadas y presentamos aquellos extractos de las entrevistas que ejemplifican dicha categoría. Identificamos a cada pareja de participantes con un número del 1 al 5 y una $\mathrm{V}$ (víctima) o A (agresor).

\section{Agresión o violencia concreta ocurrida}

Todos los entrevistados describen la violencia concreta que sufrieron durante el genocidio por parte de su agresor; en concreto, son siempre las víctimas las que lo narran (aunque los agresores están sentados al lado y tienen también la opción de contestar). Uno de ellos había destruido la casa y las tierras de su víctima, y las otras cuatro habían participado en las matanzas de los familiares de sus víctimas (hijos, maridos, hermanos...). El vínculo previo que existía entre víctimas y agresores (todos se conocían antes del genocidio) ilustra el poder de los mecanismos de desconexión moral que no solo permite cometer actos violentos contra personas anónimas, sino también contra aquellos conocidos, cercanos, con los que ha habido un contacto.

- Él destruyó mi casa durante el genocidio (silencio... se levantan y se dan un abrazo, después continúan hablando). Nos conocíamos desde niños, éramos vecinos, él incluso fue mi novio durante algún tiempo cuando éramos jóvenes. $(1 \mathrm{~V})$

- Éramos vecinos, él estaba en el grupo que mató a mis cuatro hijos y a mi marido. (2V)

- Tenemos la misma edad, éramos vecinos y profesores a tiempo parcial en el mismo colegio. Antes del genocidio éramos amigos. Él mató a mi hermano pequeño y le tiró a una letrina (un hoyo en la tierra). (3V) 
- Éramos vecinos, él era el líder de un grupo que asesinó a varios miembros de mi familia, a mis hermanos. (4V)

- Antes del genocidio éramos vecinos. Él participó en las masacres de mi familia y destruyó mis propiedades. (5V)

\section{Mecanismos de desconexión moral}

La dificultad que describen los agresores a la hora de tomar conciencia de la magnitud y gravedad de los actos que habían cometido apunta nuevamente al poder de los mecanismos de desconexión moral. Los entrevistados tardaron en caer en la cuenta (algunos incluso tras años de cárcel) en que lo que habían hecho era un crimen, incluso tras asesinatos tan cruentos como los que se dieron en Ruanda los mecanismos de desconexión son capaces de diluir la responsabilidad hasta un punto en que la narrativa sobre lo ocurrido se aleja completamente de la realidad de la violencia acontecida. Para las personas llega a ser extremadamente difícil asumir la responsabilidad sobre sus actos, que puedan referirse a lo acontecido como "crimen" ya es un indicador de asunción (lo que diluye así la etiqueta eufemística que sostenían hasta entonces), o la capacidad de nombrar lo ocurrido en primera persona sin desplazar la responsabilidad. Una vez asumida la responsabilidad, ya se convierte en motor del resto del proceso.

- Al salir de la cárcel (...) Para mí fue muy difícil empezar y reconocer lo que había ocurrido. (2A)

- Me costó mucho asumir mi crimen, reflexioné mucho mientras estaba en prisión hasta que entendí que lo que había hecho era un crimen y no estaba bien. (3A)

- Me ayudaron mucho los encuentros con supervivientes del genocidio (los encuentros que se daban durante los talleres organizados por la asociación AMI); escuchar a los supervivientes me animó a acercarme a él. (3A) 
- No había ningún tipo de esperanza en mi vida después de entender el crimen que había cometido. (4A)

\section{Perdón a uno mismo}

En cuanto al autoperdón, clasificamos las respuestas de los entrevistados en torno a cinco categorías correspondientes a las distintas fases del proceso interior que vive el agresor hasta que llega a perdonarse a sí mismo. Estas categorías son: negaciónevitación, malestar posofensa después del reconocimiento del crimen cometido, expresión de remordimiento, restauración-reparación interpersonal y restauración personal.

Negación-evitación. Los participantes hablan del miedo al contacto con la víctima por su posible reacción. Ese temor suele llevar a evitarse mutuamente, asilo que incrementó el miedo al encuentro. En ocasiones los ofensores no piden perdón porque las ideas irracionales sobre la posible reacción de la víctima se lo impiden. El agresor, desde su sentimiento de vergüenza se siente indigno de acercarse a la víctima e indigno incluso de solicitar su perdón, aunque ya se arrepienta de sus actos. Las respuestas ilustran en gran medida la tendencia a evitar a la que lleva dicha vergüenza.

- Para mí, lo más difícil fue tomar la decisión de iniciar el proceso, tener la iniciativa para ir hasta ella y pedirle perdón. Fue muy duro tomar la iniciativa... Yo era como un perro que cambia de dirección cuando ve venir algo que le aterra. Cuando me encontraba con ella la evitaba, ahora vamos en la misma dirección. (1A)

- No quería dar el primer paso porque pensaba que era muy duro. (4A)

Al principio me resultaba muy difícil perdonar, a ambos nos daba miedo el otro, no queríamos encontrarnos. (4V) Malestar posofensa después del reconocimiento del crimen cometido. Los agresores expresan el malestar en el que se encontraban sumidos tras tomar conciencia de la gravedad de los crímenes cometidos. La desesperanza de cara al futuro, la falta de horizontes y la desconfianza en la posibilidad de recibir el 
perdón de sus víctimas ocupa sus pensamientos tras asumir la responsabilidad. No obstante, ese mismo malestar sirve de impulso para el cambio; es la desesperanza la que les impele a acercarse a sus víctimas y buscar su perdón.

- Después decidí pedir perdón, pero no confiaba en que fuera a ser perdonado. $(3 \mathrm{~A})$

- Mi personalidad me impulsó a pedir perdón porque no había ningún tipo de esperanza en mi vida después de entender el crimen que había cometido. (4A)

Expresión de remordimiento. Todos nuestros entrevistados describieron cómo fue el agresor el que tomó la iniciativa para acercarse y pedir perdón. Los agresores describen esta iniciativa como lo más difícil de todo el proceso, de hecho, algunos de ellos habían vivido evitándose mutuamente durante años y negando sus crímenes. Para uno de los agresores, escuchar a otras víctimas durante los talleres le dio el impulso necesario para poder acercarse a aquella a la que había evitado durante años y expresarle su arrepentimiento. En muchos casos, la expresión de remordimiento va de la mano del reconocimiento de la verdad de lo ocurrido, verdad que algunas víctimas no habían escuchado hasta ese momento.

- Le pedí perdón después de perdonarme a mí mismo, fue lo primero que hice. $(2 \mathrm{~A})$

- Al salir de la cárcel intenté acercarme, pero ella era muy reticente. Insistí mucho y ella finalmente accedió, le pedí perdón y ella se negó. Para mí fue muy difícil empezar y reconocer lo que había ocurrido. (2A)

- Envié a un amigo para que él le explicara que quería pedirle perdón. Ella accedió y le dijo a mi amigo que yo podía ir. El tercer día de la intervención (la tercera sesión de la iniciativa de la asociación AMI) me atreví a acercarme a ella. $(4 \mathrm{~A})$

- Valoré mucho que él tuviera la iniciativa de empezar. (2V) 
- Me ayudaron mucho los encuentros con supervivientes del genocidio (los encuentros que se daban durante los talleres organizados por la asociación AMI); escuchar a los supervivientes me animó a acercarme a él. (3A)

Restauración-reparación interpersonal. Aunque la restauración del daño incrementa la sensación de justicia y facilita el proceso de perdón, cada entrevistado expresaba una vivencia diferente y particular respecto a ella. Parece que la restauración de los daños físicos, directa o indirectamente, acelerara la reparación interpersonal. El trabajo en la reconstrucción de lo dańado permite el contacto y este, a su vez, que la confianza crezca. Algunos agresores quisieron pagar sus deudas, pero no podían asumirlas y compensaron con otras tareas; otros quisieron pagar y sus víctimas, como signo de perdón, no se lo permitieron.

- Me uní a la asociación al salir de prisión y él (víctima) supo de la existencia de la asociación después de que yo fuera a pedirle perdón. Tenía que pagarle por lo que había destruido, pero no podía, así que le pedí hacer algún tipo de trabajo a cambio. $(5 \mathrm{~A})$

- Él tenía que pagarme por lo que había destruido, pero no podía, así que me pidió hacer algún tipo de trabajo a cambio. Le dije que tenía una tierra y que podría ayudarme a cultivarla mejor. Vino con un grupo de 20 personas de la asociación, exprisioneros y supervivientes. (5V)

- Para mostrar que había perdonado, le entregué los documentos donde ponía que me debía pagar por lo que había destruido, como signo de perdón verdadero. $(5 \mathrm{~V})$

- Ella no me pidió que reparara nada de lo que había dañado ni que le compensara económicamente... (1A)

- Ahora estamos serenos, nuestros corazones están estables, colaboramos para la paz y hemos construido confianza. Nos sentimos preparados para perdonar a otros. $(4 \mathrm{~V})$ 
- Le he perdonado de corazón. Antes estaba triste, ahora estamos bien, perdonar ha limpiado mi corazón, siento que después de perdonar mi corazón está libre y me siento relajada. Ahora la vida es como... normal. $(2 \mathrm{~V})$

- Lo perdoné e invitó a su familia a recibir las disculpas, él fue el padrino de boda de mi hija. (1V)

- Al principio yo le decía buenos días y ella no contestaba. Ha sido un proceso largo, al principio no había ningún tipo de confianza, ahora trabajamos juntos y compartimos actividades económicas conjuntas. (2A)

- Después de perdonarlo empezamos a colaborar, hemos reconstruido la confianza entre nosotros. (3V)

- Ahora tenemos confianza, estamos unidos, colaboramos. (5V)

Restauración personal. Dos agresores describieron cómo se perdonaron a sí mismos antes de pedir perdón a sus víctimas. Parece que el proceso de cambio personal acontece antes del movimiento hacia el otro. No es suficiente con que ellos se perdonen a sí mismos, es esa misma restauración personal la que los pone en movimiento para buscar restaurar la relación (pedir disculpas, reparación del daño, etc.).

- Le pedí perdón después de perdonarme a mí mismo; fue lo primero que hice. $(2 \mathrm{~A})$

- Me perdoné a mí mismo en prisión, antes de ir a pedirle perdón. (3A)

- Ahora me siento libre, lleno de alegría y felicidad. Tengo 61 años, pero cuando la veo siento como si tuviera 18 . (1A) 


\section{Conclusiones}

Nuestro estudio confirma la aplicabilidad de los conceptos básicos del marco teórico en este caso concreto, tanto los referidos a la presencia de mecanismos de desconexión moral como los referidos a los pasos necesarios, según la psicología del perdón, para llegar a encontrarse con las víctimas, pedir perdón y empezar un camino de reconciliación. De hecho, la asociación AMI centra su trabajo de reconciliación en combatir la desconexión moral, haciendo al sujeto responsable de sus actos y ayudándole a reflexionar sobre los valores que quiere que rijan su vida, y en ofrecer una forma de relación basada en el perdón, a uno mismo y al otro, y la reparación y recuperación de la confianza.

Las experiencias narradas por los sujetos entrevistados ponen de manifiesto que el camino desde la negación y la desconexión moral hasta el perdón y la restauración personal y social es un proceso largo y costoso, con idas y venidas.

El inicio del camino es asumir la responsabilidad y dejar de negar lo cometido. Cuando se llevaron a cabo las entrevistas, todos los agresores habían pasado ya por la fase de revisar sus acciones y reconocer sus crímenes, normalmente durante su estancia en la cárcel, cuando cesa el bombardeo de mensajes que incitan al odio y al miedo, los principales motores del conflicto violento. Las entrevistas empiezan cuando se han abandonado los mecanismos de desconexión moral, como ilustra su manejo del lenguaje, el uso de la primera persona singular y la utilización de la palabra "crimen".

Es importante también destacar que, en todos los casos, los agresores hablaban de su acción, "hice algo malo", y no de una autocondenación exagerada fruto de percibirse como intrínsecamente malos; experimentan el peso de la culpa, el remordimiento, pero todos indican que el proceso de reconciliación, una vez reconocido el crimen, sigue por perdonarse a sí mismos. Es el proceso de reconciliarse con la propia identidad el que abre la puerta al siguiente paso: entender que su acción no es el punto final del conflicto, que ellos siguen siendo personas con valores, que sufren por lo ocurrido y desean expresarlo y repararlo. Solo entonces se ven con la fuerza para 
encontrarse con su víctima, piden disculpas e intentan la restauración o la reparación del daño causado.

Como vemos, las entrevistas ilustran la relevancia del fin de la desconexión moral y la asunción de responsabilidad para poner en marcha el proceso de perdón a uno mismo, y muestran que las distintas dimensiones que el modelo de perdón a uno mismo presentado en la introducción (Cornish y Wade, 2015; Woodyatt y Wenzel, 2013) se ajustan a este proceso en una situación tan extrema como la participación en el terrible genocidio de Ruanda.

\section{Agradecimientos}

Este artículo no habría sido posible sin la generosidad, amabilidad y hospitalidad del padre Fidèle Dushimimana. Agradecemos también a Eric Ndayisaba, director de la Asociación Modeste et Innocence, que nos facilitó y organizó las entrevistas.

\section{REFERENCIAS}

Bandura, A. (1990). Selective activation and disengagement of moral control. Journal of Social Issues, 46(1), 27-46. DOI: 10.1111/j.1540-4560.1990.tb00270.x.

Bandura, A. (1999). Moral disengagement in the perpetration of inhumanities. Personality and Social Psychology Review, 3(3), 193-209. Dor: 10.1207/s15327957pspr0303_3.

Bandura, A. (2002). Selective moral disengagement in the exercise of moral agency. Journal of Moral Education, 31(2), 101- 119. DoI: 10.1080/0305724022014322.

Cornish, M. A. y Wade, N.G. (2015). A therapeutic model of self-forgiveness with intervention strategies for counselors. Journal of Counseling and Development, 93, 96-104. DOI: $10.1002 / j .1556-6676.2015 .00185 . x$. 
Dillon, R. S. (2001). Self-forgiveness and self-respect. Ethics, 112(1), 53-83. DOI: $10.1086 / 339140$.

Fisher, M. L. y Exline, J. J. (2006). Self-forgiveness versus excusing: the roles of remorse, effort and acceptance of responsibility. Self and Identity, 5, 127-146. DOI: $10.1080 / 15298860600586123$.

Hall, J. H. y Fincham, F. D. (2005). Self-Forgiveness: the stepchild of forgiveness research. Journal of Social and Clinical Psychology, 24(5), 621-637. Dor: 10.1521/ jscp.2005.24.5.621.

Gilbert, D. T., Pinel, E., Wilson, T. D., Blumberg, S. J. y Wheatley, T. P. (1998). Immune Neglect: A source of durability bias in affective forecasting. Journal of Personality and Social Psychology, 75(3), 617-38. Dor: 10.1037/0022-3514.75.3.617.

Mack, J. (1990). The Psychodynamics of victimization among groups in conflicts. En V. D. Volkan, D. A. Julios y J. V. Montville (eds.), The psychodynamics of international relationship. Vol. 1: Concepts and theories (pp. 119-129). Lexington, Mass: Lexington Books.

Sabucedo, J. M., Blanco, A. y De la Corte, L. (2003). Creencias legitimadoras de la violencia política contra los inocentes. Psicothema, 15(4), 550-555.

Smith, J. A., Flowers, P. y Larkin, M. (2009). Interpretative Phenomenological Analysis: Theory, Method, Research. Londres: Sage.

Smith, J. A. y Osborn, M. (2015). Interpretative phenomenological analysis as a useful methodology for research on the lived experience of pain. British Journal of Pain, 9(1), 41-42. DOI: 10.1177/2049463714541642.

Wenzel, M., Woodyatt, L. y Hedrick, K. (2012). No genuine self-forgiveness without accepting responsibility: Value reaffirmation as a key to maintaining positive self-regard. European Journal of Social Psychology, 42, 617-627. Dor: 10.1002/ejsp.1873. 
Woodyatt, L. y Wenzel, M. (2013). Self-forgiveness and restoration of an offender following an interpersonal transgression. Journal of Social and Clinical Psychology, 32(2), 225-259. Dor: 10.1521/jscp.2013.32.2.225.

(c) (i) (2) 